\title{
Patterns of homosexually acquired gonococcal serovars in Edinburgh 1986-90
}

\author{
H Young, A Moyes, J D C Ross, A McMillan
}

\begin{abstract}
Aim-The aim of this study was to observe the changes in gonococcal serovar pattern in homosexual men over a 5 year period.

Methods-All men who presented to the Genitourinary Medicine clinic at Edinburgh Royal Infirmary between 1986 and 1990 with homosexually acquired gonococcal infection were included in the study. Gonococcal isolates were serotyped and the temporal change in isolated serovars noted.

Results-Over the 5 year period 32 different serovars were associated with 175 homosexually acquired infections. There was a dynamic temporal change in the dominant serovars with a continual influx of new strains some of which become established in the community but most of which appeared only transiently. Rapid variation in incidence over time was observed for certain serovars while others remained at more constant levels. There was a marked association between certain serovars (Ae/Av; Back/Bropyt; Bacejk/Brpyut; Bacejk/ Brpyust; Baejk/Brpyut) and homosexually acquired infection.

Conclusions-Possible determinants for the patterns observed are discussed but the underlying mechanism is probably multifactorial.
\end{abstract}

\section{Introduction}

In the early 1980 s monoclonal antibodies specific to Protein I on the outer membrane of Neisseria gonorrhoeae were developed. ${ }^{12}$ The subsequent ability to subdivide gonococcal isolates into serovars was soon applied to study the epidemiology of gonococcal infection. ${ }^{3}$ This work has demonstrated wide geographical variation in the prevalence of different

Department of Medical Microbiology, Edinburgh University Medical School, Teviot Place, Edinburgh, EH8 9AG, UK

H Young, A Moyes

Genitourinary Medicine Unit, Department of Medicine, Edinburgh Royal Infirmary, Lauriston Place, Edinburgh, EH3 9YW

J D C Ross, A McMillan gonococcal serovars ${ }^{34}$ in addition to changes in the dominant serovars of any one region with time..$^{3-6}$ The distribution of serovars has also been noted to vary with sexual orientation with certain serovars, such as Back/Bropyt ${ }^{7}$ or IB- $2,{ }^{8}$ being associated with homosexually acquired infection. Data relating to temporal changes in serovar prevalence are, in general, less extensive and to our knowledge no information on the temporal variation in serovars associated with homosexually acquired gonorrhoea in this country has been published.

The aim of the study was to observe the prevalence of gonococcal serovars producing homosexually acquired infection over a period of 5 years and to see if any pattern could be discerned.

\section{Methods}

All isolates of Neisseria gonorrhoeae from men giving a history of homosexual contact who attended the Department of Genitourinary Medicine at Edinburgh Royal Infirmary between January 1986 and December 1990 were included in the study. Comparison was also made with the serovars isolated in the heterosexual population over the same time period.

\section{Serovar identification}

Monoclonal coagglutination reagents The serovar of each isolate was determined using two panels of monoclonal reagents. ${ }^{9}$ The Pharmacia (Ph-) panel consisted of five Protein IA specific reagents (Ar, Ao, $\mathrm{As}, \mathrm{At}, \mathrm{Av})$ and nine Protein IB specific reagents $(\mathrm{Br}$, $\mathrm{Bo}, \mathrm{Bp}, \mathrm{Bv}, \mathrm{By}, \mathrm{Bu}, \mathrm{Bs}, \mathrm{Bt}, \mathrm{Bx}$ ) and the Genetic Systems (GS-) panel consisted of seven Protein IA specific reagents ( $\mathrm{Af}, \mathrm{Ae}, \mathrm{Ad}, \mathrm{Ag}, \mathrm{Ak}, \mathrm{Ai}, \mathrm{Ah}$ ) and seven Protein IB specific reagents $(\mathrm{Ba}, \mathrm{Bc}, \mathrm{Be}, \mathrm{Bg}, \mathrm{Bh}$, $\mathrm{Bj}, \mathrm{Bk})$.

Antigen preparation Eighteen to 24 hour cultures on GC medium were harvested into $1 \mathrm{ml}$ phosphate buffered saline $\mathrm{pH} 7 \cdot 2$ to give a smooth milky suspension. This suspension was boiled for 10 minutes and allowed to cool before testing. Prepared antigen was stored at $4^{\circ} \mathrm{C}$ for up to two weeks if not tested immediately.

Test procedure Monoclonal coagglutination reagents and antigen preparations were each mixed well before testing. The tests were carried out by adding $20 \mu \mathrm{l}$ of prepared antigen suspension to $20 \mu \mathrm{l}$ 
Table Serovars isolated from 175 homosexually acquired infections 1986-90

\begin{tabular}{|c|c|c|c|c|c|c|}
\hline Serovar & $\begin{array}{l}\text { Knapp } \\
\text { nomenclature }\end{array}$ & 1986 & 1987 & 1988 & 1989 & 1990 \\
\hline Back/Bropyt & IB-1/IB-2 & $27(47 \cdot 1)$ & $7(35)$ & $3(8 \cdot 3)$ & $8(57 \cdot 1)$ & $1(2)$ \\
\hline Bacejk/Brpyust & IB-1/IB-2 & $11(20)$ & $2(10)$ & $3(8 \cdot 3)$ & 0 & $13(26)$ \\
\hline $\mathrm{Ae} / \mathrm{Av}$ & IA-4 & $3(5 \cdot 5)$ & $3(15)$ & $3(8 \cdot 3)$ & 0 & 0 \\
\hline Bajk/Bropt & IB-3/IB-6 & $1(1 \cdot 8)$ & $2(10)$ & 0 & $3(21 \cdot 4)$ & $2(4)$ \\
\hline Bak/Bropyt & IB-3/IB-6 & $1(1 \cdot 8)$ & $1(5)$ & 0 & 0 & $3(6)$ \\
\hline Beghjk/Bryvut & IB-4/IB-11 & $2(3.6)$ & 0 & $1(2 \cdot 8)$ & 0 & 0 \\
\hline Bacejk/Bpyust & IB-1/IB-2 & $1(1 \cdot 8)$ & 0 & 0 & 0 & 0 \\
\hline Aedih/Arst & IA-6 & $1(1 \cdot 8)$ & 0 & 0 & 0 & $4(8)$ \\
\hline Bacehjk/Bopyust & IB-21 & $1(1 \cdot 8)$ & 0 & 0 & 0 & 0 \\
\hline Bacehjk/Bpyust & IB-21 & $1(1 \cdot 8)$ & 0 & 0 & 0 & 0 \\
\hline Baehjk/Bpyvut & IB-8/IB-13 & $2(2 \cdot 6)$ & 0 & 0 & 0 & 0 \\
\hline Bajk/Brpt & IB-3/IB-6 & $1(1 \cdot 8)$ & 0 & 0 & 0 & 0 \\
\hline Bcgjk/Bopst & IB-5/IB-7 & $1(1 \cdot 8)$ & 0 & 0 & 0 & 0 \\
\hline Begjk/Bpyvut & IB-8/IB-18 & $2(3.6)$ & 0 & 0 & 0 & 0 \\
\hline Baejk/Brpyut & IB-3/IB-6 & 0 & $1(5)$ & $6(16 \cdot 7)$ & 0 & $10(20)$ \\
\hline Aedgkih/Arost & IA-1/IA-2 & 0 & $2(10)$ & $3(8 \cdot 3)$ & 0 & $1(2)$ \\
\hline Aed/Arst & IA-8/IA-14 & 0 & $1(5)$ & 0 & 0 & 0 \\
\hline Bajk/Brot & IB-3/IB-6 & 0 & $1(5)$ & 0 & 0 & 0 \\
\hline Bacejk/Brpyut & IB-1/IB-2 & 0 & 0 & $10(27 \cdot 8)$ & $2(14 \cdot 3)$ & $4(8)$ \\
\hline Baejk/Brpyust & IB-3/IB-6 & 0 & 0 & $2(5 \cdot 6)$ & 0 & 0 \\
\hline Bacej/Brpyust & IB-10/IB-16 & 0 & 0 & $1(2 \cdot 8)$ & 0 & 0 \\
\hline Bacjk/Bropst & IB-1/IB-2 & 0 & 0 & $1(2 \cdot 8)$ & 0 & 0 \\
\hline Bacjk/Bopt & IB-1/IB-2 & 0 & 0 & $1(2 \cdot 8)$ & 0 & 0 \\
\hline Back/Bropyst & IB-1/IB-2 & 0 & 0 & $1(2 \cdot 8)$ & 0 & 0 \\
\hline Bgk/Bropyvt & IB-8/IB-18 & 0 & 0 & $1(2 \cdot 8)$ & 0 & 0 \\
\hline Bacjk/Bropt & IB-1/IB-2 & 0 & 0 & 0 & $1(7 \cdot 1)$ & 0 \\
\hline Beghjk/Bpyvut & IB-4/IB-11 & 0 & 0 & 0 & 0 & $3(6)$ \\
\hline Bajk/Broput & IB-3/IB-6 & 0 & 0 & 0 & 0 & $3(6)$ \\
\hline Behjk/Byvut & IB-15/IB-27 & 0 & 0 & 0 & 0 & $3(6)$ \\
\hline Bck/Bys & IB-19/IB-22 & 0 & 0 & 0 & 0 & $1(2)$ \\
\hline Baejk/Brpyu & IB-3/IB-6 & 0 & 0 & 0 & 0 & $1(2)$ \\
\hline Bcegjk/Bpyust & IB-5/IB-7 & 0 & 0 & 0 & 0 & $1(2)$ \\
\hline Total & & 55 & 20 & 36 & 14 & 50 \\
\hline
\end{tabular}

^Each serovar may correspond to one or more serovars using the panel and nomenclature of Knapp. ${ }^{14}$

of each coagglutination reagent on defined areas of large glass slides. Slides were rocked gently for two minutes, and coagglutination reactions were read using an oblique light against a dark background.

Scoring results Reactions were scored according to the strength of the coagglutination observed. They were graded negative $(-)$ if they showed a smooth milky background; borderline $( \pm)$ if they showed a slightly granular milky background; weakly reactive $(1+)$ if they showed a granular background with some clearing; or moderately reactive $(2+)$, strongly reactive $(3+)$, or very strongly reactive $(4+)$ if they showed increasing degrees of clumping and background clearing.

Designation of serovars A serovar is defined as the pattern of reactivity of a test strain with a given set of monoclonal antibodies specific for either the protein I-A or I-B subtype. Each serovar is therefore depicted by an upper case letter A or B followed by lower case letters representing positive reactions with the corresponding coagglutination reagents. ${ }^{10}$ Reactions of $1+$ or more were scored positive in designating a strain to a serovar.

Statistical analysis Statistical analysis was by the chi square test with Yates' correction.

\section{Results}

The numbers (and percentages) of different serovars isolated each year and total number of homosexually acquired infections are shown in the table. It can be seen that new serovars were continually appearing over the study period with a small number beginning to be established and the rest being only transient. Over the 5 year period the total of 175 infections were caused by 32 different serovars: 29 protein IB serovars accounted for $88 \%$ (154) of the 175 isolates and three protein IA serovars for $12 \%$ (21).

Five serovars were isolated at least three times per year in 2 or more years-Ae/Av, Bacejk/Brpyust, Back/Bropyt, Bacejk/Brpyut and Baejk/Brpyut. The changing prevalence of these serovars by year is illustrated in fig 1 . The prevalence of three serovars changed significantly over the 5 year period-Back/ Bropyt, Bacejk/Brpyust and Bacejk/Brpyut. Comparison with the serovars from heterosexually acquired gonorrhoea (fig 2) confirmed that all five of the above serovars were significantly associated with homosexual transmission over the 5 year period. Although these five serovars were strongly associated with homosexual infection they also occurred in the heterosexual community. However, within the 
Serovar by Year

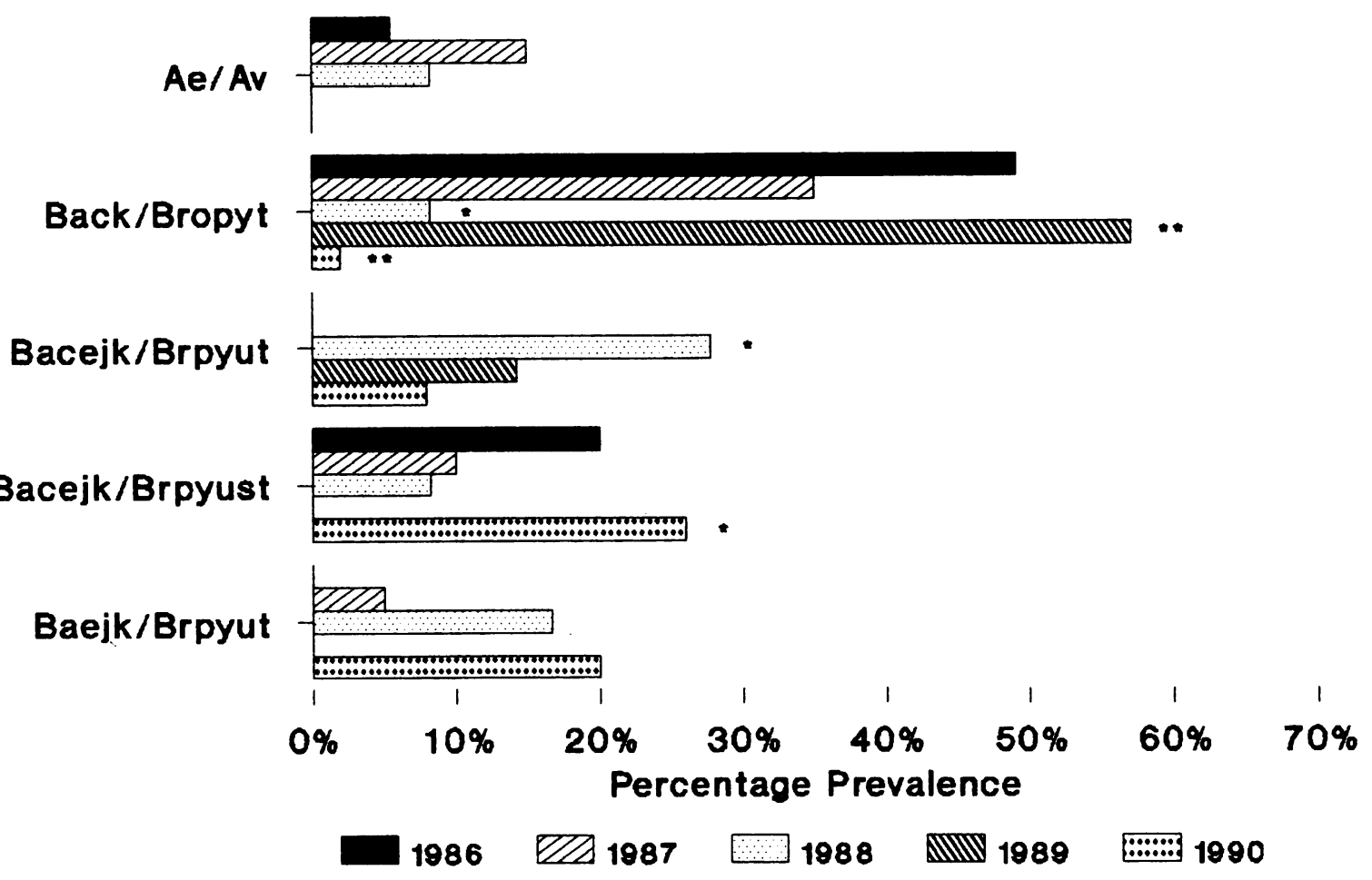

Figure 1 Temporal change in gonococcal serovars 1986-90. Significant year to year changes marked $*(p<0.05)$ and $\star \star(p<0.01)$.

heterosexual group the percentage prevalence of certain serovars had a high male:female ratio $(M: F)$, for example, Back/Bropyt (M:F ratio 1·6:1), Ae/Av (M:F ratio $2 \cdot 4: 1$ ).

\section{Discussion}

In common with previous studies there was a predominance of serogroup WII/III (protein IB) infections in the homosexual group. ${ }^{37}$

From fig 1 it is evident that there is a marked variation in serovar prevalence with time in this patient group. Certain serovars remain at relatively constant low levels (Ae/Av, Baejk/Brpyut) while others have wide and rapidly varying levels (Back/ Bropyt, Bacejk/Brpyut, Bacejk/Brpyust). These wide variations in homosexually acquired infection have not been previously reported in this country.

The reasons for this diversity in serovars and the greater success of some serovars in becoming established are not clear. Previous studies have shown that $\mathrm{Ae} / \mathrm{Av}$ and $\cdot \mathrm{Baejk} / \mathrm{Brpyut}$ have a relatively high level of chromosomally mediated resistance to penicillin with more isolates having a MIC $\geq 0.5 \mathrm{mg} / 1$ than < $0.5 \mathrm{mg} / 1$ when compared with most other strains. ${ }^{6}$
The ability of these two serovars to persist in the homosexual population may be related to this antibiotic resistance. However, Back/Bropyt has persisted over a 5 year period despite being significantly more susceptible to penicillin.

The cause of the year to year variation in the levels of serovars may also be mediated via individual strain infectivity or virulence. In addition there has been a change in sexual behaviour over the study period following a health education campaign directed against human immunodeficiency virus infection. This has led to safer sexual practices and a fall in the number of cases of gonorrhoea. ${ }^{11}$ This reduction in high risk sexual activity presumably makes it more difficult for new strains to survive in a population that was previously more promiscuous.

Morse et al ${ }^{12}$ reported an association between homosexually acquired infection and a mutation ( $m$ tr) that encodes for increased resistance to both hydrophilic and hydrophobic molecules such as penicillin and erythromycin. It was postulated ${ }^{12}$ that possession of the mtr mutation may enhance survival of gonococci in the hydrophobic environment of the rectum, most likely as a result of decreased cell envelope permeability; there is, however, little direct 


\section{Serovar}

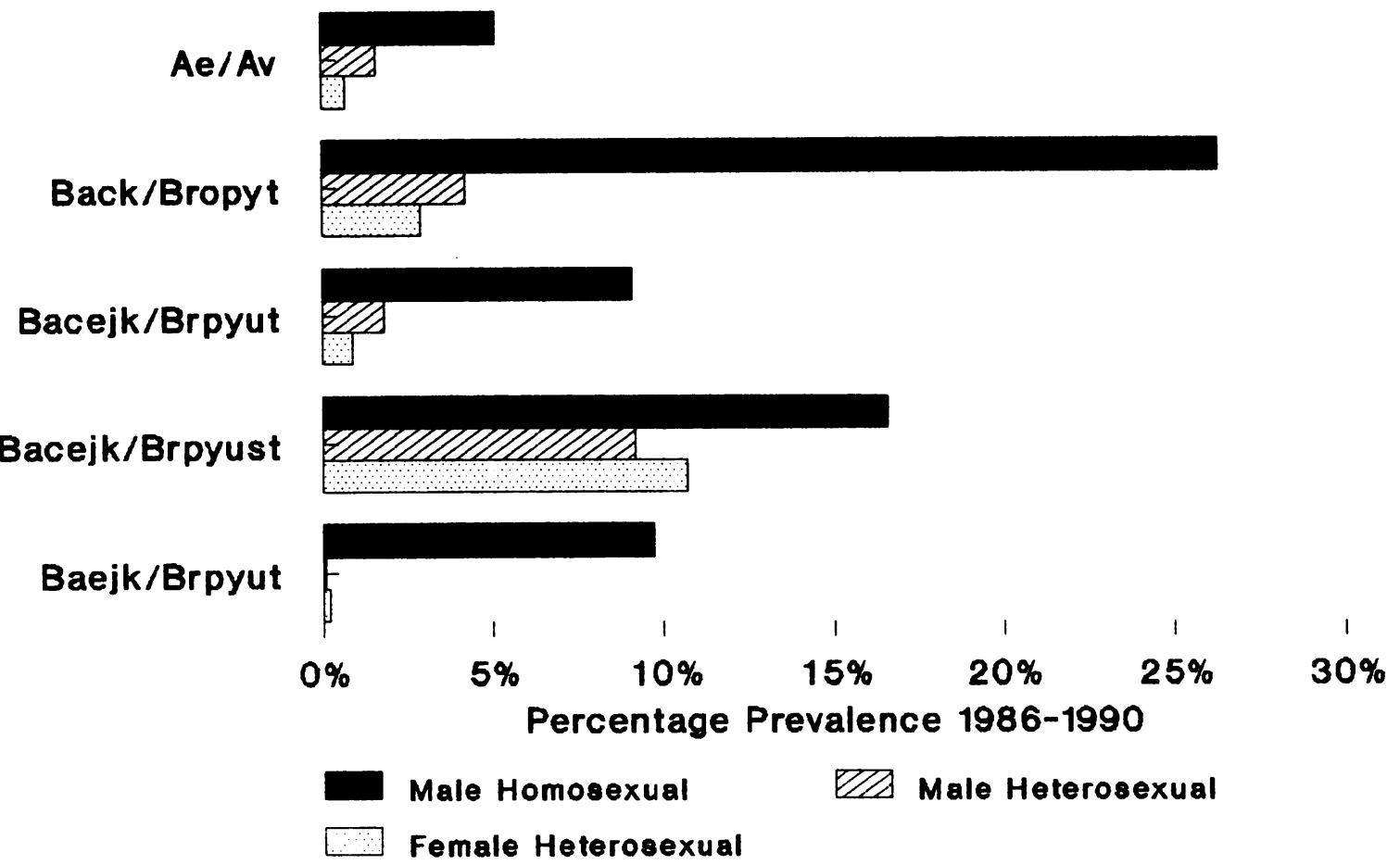

Figure 2 Gonococcal serovars grouped by sexual orientation of patient.

evidence for this. Whereas a decrease in permeability may constitute a selective advantage in the hydrophobic environment of the rectum, in other situations decreased permeability may be a disadvantage in that it might limit the flow of nutrients into the cell and restrict growth. Presumably complex host and bacterial factors will determine the relative benefits of a particular strain characteristic in a given environment and influence the ability of a strain to compete in the circulating pool of isolates causing infection within a particular community.

The presence of transient populations of particular serovars has been previously described but not for homosexually acquired infections over such a prolonged time period. ${ }^{6}$ It has been postulated that all strains are intrinsically transient and strains only persist by frequent reintroduction from neighbouring areas. ${ }^{13}$ Another theory proposes that eventually a population will develop protective immunity to a particular strain which results in the strain dying out. ${ }^{4}$

Three new serovars were isolated exclusively from homosexual men on two or more occasions in 1990Bajk/Broput, Beghjk/Bpyvut and Behjk/Byvut. It remains to be seen whether any or all of these will become established over subsequent years.
The association between gonococcal serovar and sexual activity suggests a use for serovar determination as a marker of homosexually acquired infection. For example in 198619 out of the 21 heterosexual isolates of Back/Bropyt were male, strongly suggesting that some of these men acquired their infection from homosexual contact. Most "homosexual" serovars also appear in the heterosexual community, however, albeit at low levels. Because of the dynamic nature of the serovars continuous surveillance within any one area is required to identify strains associated with homosexually acquired infection.

The use of two panels of monoclonal antibodies is more suited to this detailed epidemiological surveillance as certain serovars can be further subdivided. For example the three major serovars, Bacejk/Brpyust, Back/Bropyt, Bacejk/Brypyut and five minor serovars (table) would all be classified as IB-1 or IB-2 with the standard GS panel. ${ }^{14}$

In conclusion, there are large variations in the prevalence of different gonococcal strains over a 5 year period with some strains persisting at low levels while others appear and disappear. The reasons for these observations are unclear but are almost certainly multifactorial. If strains are continually monitored in any one area then serovar analysis may 
be used as a marker for homosexually acquired infection.

We thank Dr Solgun Bygdeman, Karolinska Institute Sweden, Dr Catherine Ison, St Mary's Hospital, London and Dr Richard Rodgers, Syva, California for supplying the monoclonal antibodies used in this study.

\section{Address correspondence to Dr H Young.}

1 Tam MR, Buchanan TM, Sandstrom EG, et al. Serological classification of Neisseria gonorrhoeae with monoclonal antibodies. Infect Immun 1982;36:1042-53.

2 Sandstrom E, Lindell P, Harfast B, Blomberg F, Ryden A-C, Bygdeman S. Evaluation of a new set of Neisseria gonorrhoeae serogroup $W$-specific monoclonal antibodies for serovar determination. In: Schoolnik GK, Brooks GF, Falkow S, Frasch CE, Knapp JS, McCutchan JA, Morse SA, eds. The Pathogenic Neisseria. Washington DC: American Society for Microbiology, 1985:26-30.

3 Bygdeman S. Polyclonal and monoclonal antibodies applied to the epidemiology of gonococcal infection. In: Young $\mathrm{H}_{\text {, }}$ McMillan A, eds. Immunological Diagnosis of Sexually Transmitted Diseases. New York: Marcel Dekker, 1987:117-65.

4 Plummer F, Bruhhan R. Gonococcal redicivism, diversity and ecology. Rev Infect Dis 1987;9:846-50.

5 Young $\mathrm{H}$, Moyes A, Robertson DM, et al. Gonococcal infection within Scotland: Antigenic heterogeneity and antibiotic susceptibility of infecting strains. Eur J Immunol 1990;6:1-8.
6 Knapp J, Holmes K, Bonin P, Hook E. Epidemiology of gonorrhoea: distribution and temporal changes in auxotype/ serovar classes of Neisseria gonorrhoeae. Sex Transm Dis 1987;14:26-32.

7 Coghill D, Gaitonde R, Kelly G, Young H. Serological classification of Neisseria gonorrhoeae. Serovars associated with homosexually acquired infection. In: Poolman J, Zanen HC, Meyer TF, Heckels JE, Mäkelä PRH, Smith H, Beuvery EC, eds. Gonococci and Meningococci. Dordrecht: Kluwer Academic Publishers, 1988:63-71.

8 Woodford N, Bindayma KM, Easman CSF, Ison CA. Associations between serotype and susceptibility to antibiotics of Neisseria gonorrhoeae. Genitourin Med 1989;65:86-91.

9 Coghill D, Young H. Serological classification of Neisseria gonorrhoeae with monoclonal antibody coagglutination reagents. Genitourin Med 1987;63:225-32.

10 Bygdeman S, Gillenius E-C, Sandstrom E. Comparison of two different sets of monoclonal antibodies for the serological classification of Neisseria gonorrhoeae. In: Schoolnik GK, Brooks GF, Falkow S, Frusch CE, Knapp JS, McCutchan JA, Morse SA, eds. The Pathogenic Neisseria. Washington DC: American Society for Microbiology, 1985:31-6.

11 Carne C, Weller I, Johnson A, et al. Prevalence of antibodies to human immunodeficiency virus, gonorrhoea rates and changed sexual behaviour in homosexual men. Lancet 1987;ii:656-8.

12 Morse S, Lysko P, McFarland L, et al. Gonococcal strains from homosexual men have outer membranes with reduced permeability to hydrophobic molecules. Infect Immun 1982; 37:432-8.

13 Sarafian S, Knapp J. Molecular epidemiology of gonorrhoea. Clin Microbiol Rev 1989;2:S49-S55.

14 Moyes A, Young H. Epidemiological typing of Neisseria gonorrhoeae: a comparative analysis of three monoclonal antibody serotyping panels. Eur J Epidemiol 1991 (in press).

Accepted for publication 22 March 1991 